Article

\title{
Hypoglicemic and Hypolipedimic Effects of Ganoderma lucidum in Streptozotocin-Induced Diabetic Rats
}

\author{
Erna Elisabeth Bach ${ }^{1, *(1)}$, Edgar Matias Bach $\mathrm{Hi}^{2}{ }^{\text {(1) }}$, Ana Maria Cristina Martins ${ }^{3}$, \\ Paloma A. M. Nascimento ${ }^{4}$ and Nilsa Sumie Yamashita Wadt 5 (iD) \\ 1 Biomedical Sciences, Health Department, UNINOVE (Universidade Nove de Julho), São Paulo 01156-050, \\ São Paulo, Brazil \\ 2 Experimental Biochemistry Academic Nucleum (NABEX), UNILUS (Lusiada University Center), \\ Santos 11050-071, São Paulo, Brazil; edgarbach@gmail.com \\ 3 Biological Institute, São Paulo 04014-900, São Paulo, Brazil; crisfm@biologico.sp.gov.br \\ 4 Biomedical Sciences, Health Department, Scientific Research Student, UNINOVE (Universidade Nove de \\ Julho), São Paulo 01156-050, São Paulo, Brazil; andrade.nascimento@bol.com.br \\ 5 Pharmacy, Health Department, Sciences, UNIP (Universidade Paulista), Jundiaí 13214-525, São Paulo, Brazil; \\ nilwadt@gmail.com \\ * Correspondence: ernabach@gmail.com; Tel.: +55-11-99944-9357
}

Received: 30 June 2018; Accepted: 19 July 2018; Published: 28 July 2018

\begin{abstract}
Background: Ganoderma lucidum (Leyss. Ex. Fr) Karst is a basidiomycete mushroom that has been used for many years as a food supplement and medicine. In Brazil, National Health Surveillance Agency (ANVISA) classified Ganoderma lucidum as a nutraceutical product. The objective of the present work was to observe the effects of an extract from Ganoderma lucidum in rats treated with streptozotocin, and an agent that induces diabetes. Method: Male Wistar rats were obtained from the animal lodging facilities of both University Nove de Julho (UNINOVE) and Lusiada Universitary Center (UNILUS) with approval from the Ethics Committee for Animal Research. Animals were separated into groups: (1) C: Normoglycemic control water; (2) CE: Normoglycemic control group that received hydroethanolic extract (GWA); (3) DM1 + GWA: Diabetic group that received extract GWA; and (4) DM1: Diabetic group that received water. The treatment was evaluated over a 30-day period. Food and water were weighted, and blood plasma biochemical analysis performed. Results: G. lucidum extract contained beta-glucan, proteins and phenols. Biochemical analysis indicated a decrease of plasma glycemic and lipid levels in DM rats induced with streptozotocin and treated with GWA extract. Histopathological analysis from pancreas of GWA-treated DM animals showed preservation of up to $50 \%$ of pancreatic islet total area when compared to the DM control group. In plasma, Kyn was present in diabetic rats, while in treated diabetic rats more Trp was detected. Conclusion: Evaluation from G. lucidum extract in STZ-hyperglycemic rats indicated that the extract possesses hypoglycemic and hypolipidemic activities. Support: Proj. CNPq 474681/201.
\end{abstract}

Keywords: diabetes; ganoderma; beta-glucan; phenols; kynurenine; tryptophan

\section{Introduction}

Ganoderma lucidum (Fr.) Krast, a basidiomycete belonging to the Ganodermataceae family, is one of the most famous traditional Chinese medicinal herbs, which has been used as a food and in folk medicine [1]. Fruiting bodies of these fungi are naturally produced but are not sufficient for commercial use [2], however, using the Jun-Cao farming method, it is possible to achieve a volume able to supply the market demand [3]. In Brazil, some people have produced this fungus using the Jun-Cao method, 
and in the country, it is classified as a nutraceutical product by ANVISA (National Agency of Health Surveillance) [4]. The mushroom is a popular folk medicine for the prevention or treatment of diseases such as hepatitis, hypertension, hypercholesterolemia, arthritis and bronchitis. In addition, G. lucidum presents a variety of biological activities, such as: immunostimulant, antimicrobial, anti-inflammatory, anti-hyperglycemic, hepatic and renal protection, antioxidant and antiviral effects [5-7]. Different kinds of bioactive polysaccharides have been extracted and isolated from the fruiting bodies of different Ganoderma species and represent a structurally diverse class of biological macromolecules with a wide-range of physiological properties. Wadt et al. [8] described the presence of beta glucan, proteins, water soluble heteropolysaccharides and phenols in extracts of Ganoderma lucidum from São Paulo.

The objective of the present work was to evaluate the effect of chemical compounds found in Ganoderma lucidum for rats with streptozocin-induced diabetes mellitus.

\section{Material and Methods}

\subsection{Extract from Ganoderma lucidum}

The fruiting bodies of G. lucidum were collected in São Paulo, Brazil and after dried, were finely milled in a hammer mill equipped with a $1 \mathrm{~mm}$ mesh stainless steel sieve.

Powdered mushroom was submitted to two methods for extracting: Extract 1-mass homogenate $(100 \mathrm{~g})$ in $100 \mathrm{~mL}$ of water, kept at $60^{\circ} \mathrm{C}$ for one hour (GHotW) and then filtered with paper filter; Extract 2-50 g of G. lucidum was percolated with alcohol 70\% (GAlc) for one week, filtered, fully extracted and concentrated until the volume of $50 \mathrm{~mL}$, and kept in bottles until further use.

For oral administration, the GWA extract (GWater-Alcohol or Hydroethanolic extract) was obtained from a mixture of $80 \%$ of Extract 1 and $20 \%$ of Extract 2 . In a work previously published by this group, Wadt et al. [8] described that hydroethanolic extract (GWA) did not exhibit acute toxicology in mice.

Extract was submitted to proteins [9], phenols [10] and beta-glucan quantification by Lever method [11]. After quantifying, phenols and ganoderic acid were analyzed by HPLC. Phenolic compounds and Ganoderic acid were separated in a High performance liquid chromatograph (HPLC) system (model Young Lin YL 9300, Young Lin Bldg, Hogye-dong, Anyang, Korea) equipped with a quaternary gradient pump unit, an UV-vis detector and the column oven (YL9330, Young Lin Bldg, Hogye-dong, Anyang, Korea). The analytical column used was a Kinetex C18 (Phenomenex) ( $4.6 \mathrm{~mm} \times 250 \mathrm{~mm}$ i.d., $5 \mathrm{um}$ ). The wavelength for UV detection was $254 \mathrm{~nm}$. Elution was carried out at a flow rate of $1.0 \mathrm{~mL} / \mathrm{min}$ at $35{ }^{\circ} \mathrm{C}$. The mobile phase A consisted of methanol and the mobile phase B was $0.1 \%$ of acetic acid in water. The injection volume was $20 \mathrm{uL}$. The standart phenolic compounds were purchased from Sigma (Merck, Rio de Janeiro, Brazil) (coumaric acid, ferulic acid, rutin, cafeic acid, quercetin, kaempferol) and dissolved in HPLC grade (methanol). Ganoderic acid A $(\mathrm{AcG})$ from Sigma was dissolved in methanol, achieving final concentration of 100, 50 and $25 \mathrm{ug} / \mathrm{mL}$. For identification was used specific retention times and the peak areas were automatically measured by software Clarity, obtaining the calibration curve.

\subsection{Animals Testing}

Male Wistar rats aged four weeks and weighing 250 to $300 \mathrm{~g}$ were obtained from bioterium of both University Nove de Junho (UNINOVE) and Lusiada Universitary Center (UNILUS). The animals were kept in polypropylene cages (two to three animals per cage) covered with metallic grids in a room maintained at $23{ }^{\circ} \mathrm{C}, 55 \pm 10 \%$ relative humidity and a $12 \mathrm{~h}$ light/dark cycle. The animals had free access to food and water for two weeks before beginning the study. The UNINOVE and UNILUS Ethics Committee for Animal Research approved the protocols used in this study (UNINOVE process numbers: 34/2010 and 20/2012; UNILUS process number: 02/2012). All animals were weighed during the experiment. 


\subsection{Diabets with Streptozotocin}

Animals were divided into four groups of five rats. In two groups, the animals were fasted for 12 hours and chemical diabetes was induced through an intraperitoneal injection of streptozotocin (50 mg $/ \mathrm{kg}$ ) (STZ, Sigma). The STZ solution was prepared immediately prior injection by dissolving the drug in a fresh, cold citrate buffer, $\mathrm{pH} 4.5$. After $72 \mathrm{~h}$, blood glucose levels were measured using a portable glucose meter (One Touch II; Johnson and Johnson, São Paulo, Brazil). For such, the distal part of the tail was gently snipped; the first blood drop was discarded and the second was absorbed by a test strip inserted in the glucose meter. Rats were considered diabetic when the blood glucose level was at least $250 \mathrm{mg} / \mathrm{dL}$. To avoid possible hypoglycemia, the animals received oral solution of dextrose $5 \%$ ad libtum only for the first $48 \mathrm{~h}$ after induction.

Groups of rats were separated as following: (1) C: Normoglycemic control that received water by gavage; (2) CE: Normoglycemic control group that received GWA extract; (3) DM1 + GWA: Diabetic group that received extract; and (4) DM1: Diabetic group that received water, with dose of $(1 \mathrm{~mL} / \mathrm{Kg} /$ day) for all groups. The groups were evaluated for 30 days. Food and water consumption were measured every two days. Blood glucose levels and weight were evaluated twice a week, always at 11:00 a.m. At the end of the experimental period, the animals were euthanized with a lethal dose of a cocktail containing ketamine $(1 \mathrm{mg})$ and xylazine $(5 \mathrm{mg})$. Thoracotomy was performed. Blood was collected from the left ventricle and centrifuged. The plasma was removed and stored at $-20^{\circ} \mathrm{C}$ for no longer than three days before the assay. Total cholesterol, triglycerides, urea and creatinine were measured using test kits (Labtest Diagnostica, Lagoa Santa, Minas Gerais, Brazil). The variance analysis was performed by the One Way ANOVA test, following T Student Test $(p<0.05)$.

\subsection{Histopathology}

After euthanasia, pancreas was removed, rinsed with water, fixed in a $10 \%$ buffered formalin solution and embedded in paraffin wax. Sections measuring $5 \mu \mathrm{m}$ in thickness were prepared and stained with hematoxylin and eosin. The three best sections from each animal were submitted to microscopic examination. Five non-consecutive areas of each sample were photographed in microscope with digital camera and polarizer (Carl Zeiss, model Axion Scope A1, Oberkochen, Germany) and analyzed using the software (Carl Zeiss, Zen 2012, Oberkochen, Germany).

\subsection{Evaluation of Amino Acid in Plasma}

$500 \mathrm{uL}$ of plasma from each animal was precipitated with ammonium sulfate up to $60 \%$, to remove the globulin, remaining over-night in the refrigerator. After centrifugation ( $3400 \mathrm{rpm}, 5 \mathrm{~min}$, eppendorf), precipitates were resuspended in phosphate buffer $\mathrm{pH}=7$ and dialyzed (Tubbing MW 10,000 daltons) for the removal of the salt used. Samples were filtered in millipore $0.25 \mathrm{um}$, and $20 \mathrm{uL}$ was injected into HPLC. YL-9300 UV-coupled HPLC instrument $254 \mathrm{~nm}$, C18 Luna $25 \mathrm{~cm} \times 4.5 \mathrm{~mm}$ reverse phase column, temperature $27-30^{\circ} \mathrm{C}$. Separation was done in the following mobile phase: buffer sodium acetate $10 \mathrm{mM}$ in MilliQ water (A) and acetonitrile (B): $0-1 \mathrm{~min}(20 \% \mathrm{~B}) ; 1.01-1.5 \mathrm{~min}$ $(5 \% \mathrm{~B}) ; 1.51-8 \mathrm{~min}(4 \% \mathrm{~B})$. The flow rate was kept constant at $1 \mathrm{~mL} / \mathrm{min}$ and peaks were detected at $254 \mathrm{~nm}$. All chemicals reagents used in the analysis, such as acetonitrile and acetate buffer we purchased from Sigma and Merck, (Rio de Janeiro Brazil), with high purity levels. The standards used were Kynerunin-Kyn (20 uM), Tryptophan-Trp (20 uM), Cysteine-Cys (10 mM), Arginine-Arg $(10 \mathrm{mM})$, Metionine-Met (10 mM), Proline-Pro (10 mM), Valine-Val (10 mM), Alanine-Ala (10 mM), Phenilalanine-Phe $(10 \mathrm{mM})$, Tyrosine-Tyr $(10 \mathrm{mM})$ from Sigma and Merck. All were evaluated and separated by HPLC based on the peak at said retention time (Rt) and height peak in millivolt $(\mathrm{mV})$ or concentration in $\mathrm{uM}$ or ug. 


\section{Results}

\subsection{Biochemical Analysis}

Basidiocarp form has colored pileus (brown) and concentric zones on the surface of the pileus that can identify G. lucidum. The fruiting body is rigid and extraction with hot water is important, for elicitation of polysaccharide along with phenols. Wadt et al. [8] demonstrated that the hydroethanolic extract has a high concentration of beta-glucan along protein and phenol (Table 1), added the fact that the dose assessed was not toxic to animal.

Table 1. Concentration of beta-glucan, free sugar, proteins and phenols $(\mathrm{mg} / 1 \mathrm{~g}$ mushroom) in extract of Ganoderma lucidum.

\begin{tabular}{lcccc}
\hline Sample & $\begin{array}{c}\text { Beta-Glucan } \\
(\mathbf{1}, \mathbf{3} ; \mathbf{1 - 6 )}\end{array}$ & $\begin{array}{c}\text { Free Sugar } \\
\text { Alfa/Beta Glucan }\end{array}$ & $\begin{array}{c}\text { Proteins } \\
\text { (BSA) }\end{array}$ & Phenol (Chlorogenic Acid) \\
\hline Ganoderm (GWA) & $97.2^{\mathrm{a}, *}$ & $25.80^{\mathrm{a}, *}$ & $0.75^{\mathrm{a}, *}$ & $1.35^{\mathrm{a}, *}$ \\
\hline${ }^{*}$ Mean from five samples of fungi. ${ }^{\mathrm{a}}$ Letter in columns indicates that all value in samples were the same. Test Tukey \\
(ANOVA).
\end{tabular}

By HPLC analysis, we verified the presence of coumaric acid $(1.46 \mathrm{ug} / \mathrm{mL}) ; 0.20 \mathrm{ug} / \mathrm{mL}$ of cafeic acid; $18.19 \mathrm{ug} / \mathrm{mL}$ of ferulic acid; $2.68 \mathrm{ug} / \mathrm{mL}$ of Kercetin; $12.21 \mathrm{ug} / \mathrm{mL}$ of rutin and $15.79 \mathrm{ug} / \mathrm{mL}$ of ganoderic acid in the extract.

\subsection{Animals with Diabetes}

During the experiment (30 days), the animals were submitted to weighing at different times, and Figure 1 displays the variation between weights. The animals in the control group (C) had a weight gain around $27.4 \mathrm{~g}$, while the group that received only GWA extract (in figure CE) had an increase of only $19 \mathrm{~g}$. Animals from DM1 + GWA groups had a weight loss of $6.8 \mathrm{~g}$ when compared with DM1 animals, where the major loss is around $30.80 \mathrm{~g}$.

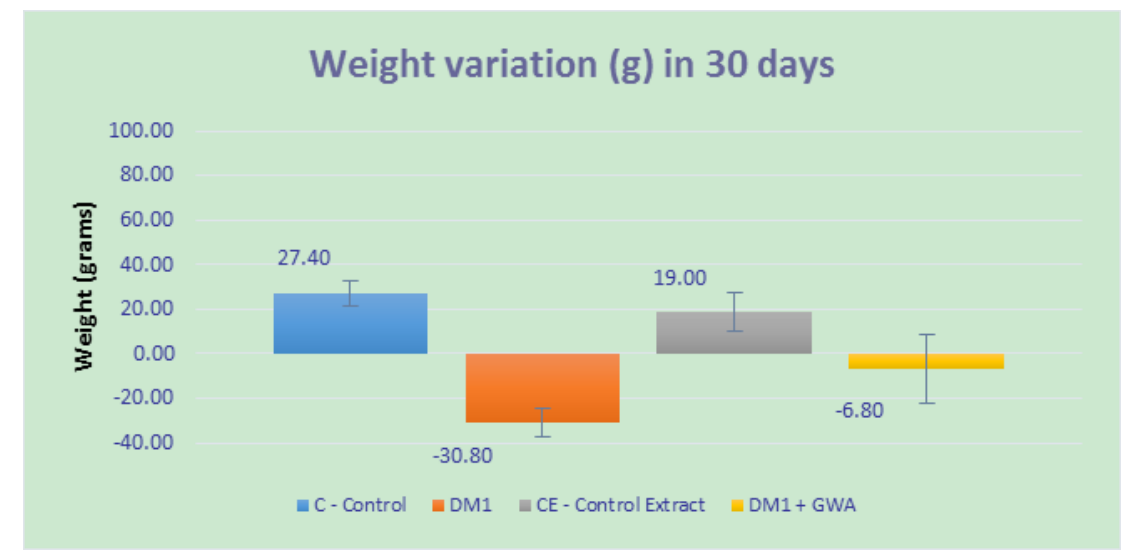

Figure 1. Weight variation (in grams) from animals since beginning of treatment until experimental end. $p<0.05$ between C and CE groups; $p<0.01$ between DM1 and DM1 + GWA (hydroethanolic extract) groups.

When glycemia is observed, Ganoderma extract presented a blood glucose level decreasing effect within the first $48 \mathrm{~h}$ after treatment and diminishing over time until the end of 30 days (Figure 2). 


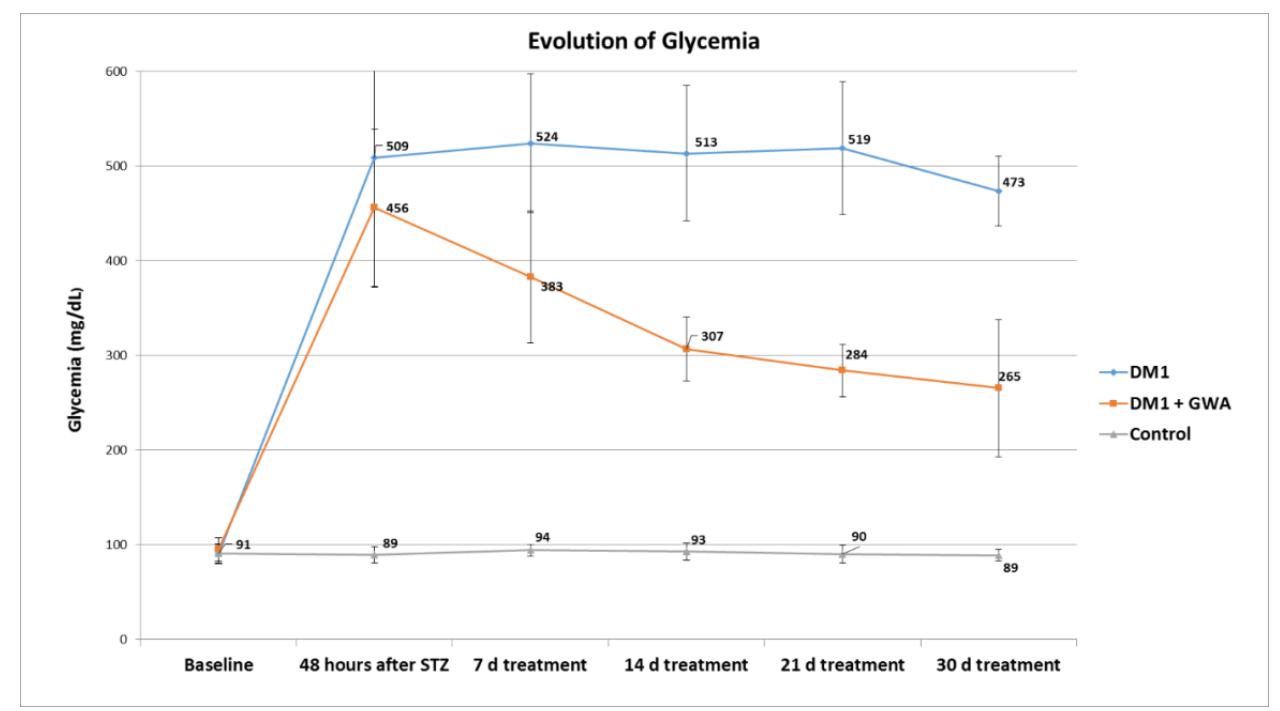

Figure 2. Blood glucose levels evolution during 30 days from Control, DM1 and DM1 + GWA groups. $p<0.01$ between DM1 and DM1 + GWA groups.

Biochemical analysis also showed an effect of a decrease of total cholesterol, triglycerides (tendency), urea and creatinine in rats treated with Ganoderma and inoculated with Streptozotocin (Table 2). Histopathological analysis from pancreas of GWA-treated DM animals showed preservation of up to $50 \%$ of pancreatic islet area when compared to DM control group (Table 3).

Table 2. Plasma biochemical analysis from rats submitted to treatments.

\begin{tabular}{|c|c|c|c|c|}
\hline Treatments * & Total Cholesterol (mg/dL) & $\begin{array}{c}\text { TAG (Triglycerides) } \\
\text { (mg/dL) }\end{array}$ & Urea (mg/dL) & $\begin{array}{l}\text { Creatinine } \\
(\mathrm{mg} / \mathrm{dL})\end{array}$ \\
\hline C & $74 \pm 10$ & $91 \pm 18$ & $32 \pm 3$ & $0.55 \pm 0.11$ \\
\hline DM1 & $101 \pm 3$ & $102 \pm 40$ & $57 \pm 2$ & $0.83 \pm 0.09$ \\
\hline $\mathrm{CE}$ & $60 \pm 6$ & $77 \pm 23$ & $36 \pm 3$ & $0.65 \pm 0.01$ \\
\hline DM1 + GWA & $73 \pm 12$ & $98 \pm 4$ & $45 \pm 2$ & $0.30 \pm 0.09$ \\
\hline statistic & $\begin{array}{c}\text { C and CE } p<0.05 \text { DM1 } \\
\text { and DM1 + GWA } p<0.01\end{array}$ & Tendency to decrease & $\begin{array}{l}\text { DM1 and DM1 + } \\
\text { GWA } p<0.01\end{array}$ & $\begin{array}{l}\text { DM1 and DM1 + } \\
\text { GWA } p<0.01\end{array}$ \\
\hline
\end{tabular}

* C: Normoglycemic control that received water by gavage; CE: Normoglycemic control group that received hydroethanolic extract (GWA) extract; DM1 + GWA: diabetic group that received extract; and DM1: diabetic group that received water.

Table 3. Measurements of islets of Langerhans from rats submitted to treatments.

\begin{tabular}{ccc}
\hline Treatments & Mean Islet Area $\left(\mathbf{u m}^{2}\right)^{*}$ & Mean Number of Nuclei per Islet \\
\hline C & 192.56 & $69.5^{* *}$ \\
DM1 & 3.40 & $15^{* * *}$ \\
CE & 112.84 & $69.8^{* *}$ \\
DM1 + GWA & 96.50 & $88.5^{* *}$
\end{tabular}

* mean of 5 rats. Legend: $\mathrm{C}=$ control; DM1 = diabetic; $\mathrm{CE}=$ Control + Ganoderma extract; DM1 + GWA = diabetic + Ganoderma extract. ${ }^{* *}$ Statistically nonsignificant; ${ }^{* * *}$ statistically significant ANOVA, level of significance $=0.05$.

\subsection{Evaluation of Amino Acid in Plasma}

Amino acid patterns were separated on HPLC (YL-9300) where they showed different retention times (Rt), following the mobile phase and method temperature, such as: $\operatorname{Trp}=2.18 \mathrm{~min}$; Kyn $($ Kynurenin $)=2.09 \mathrm{~min} ;$ Cys $=2.73 \mathrm{~min} ;$ Arg $=2.83 \mathrm{~min} ;$ Met $=3.00 \mathrm{~min} ;$ Pro $=4.25 \mathrm{~min}$; $\mathrm{Val}=4.38 \mathrm{~min} ; \mathrm{Ala}=4.41 \mathrm{~min} ; \mathrm{Phe}=4.55 \mathrm{~min} ; \mathrm{Tyr}=4.65 \mathrm{~min}$. Observing the plasma content of the 
animals after precipitation, dialysis and filtration along with the HPLC, several peaks were obtained, however, only 2 Rt were recognized among the standards of amino acids among others unknown.

The amino acid Trp was detected in all groups of this study. However, its concentration was higher in groups treated with GWA extract. In the CDM group, Trp concentration decreased, revealing the presence of Kyn (Table 4).

Table 4. Composition of amino acids present in plasma of rats submitted to treatments, evaluated by HPLC.

\begin{tabular}{cccc}
\hline & $\boldsymbol{r}$ & Kyn & Trp \\
\hline Treatments & $\mathrm{Rt}=1.30$ & $\mathrm{Rt}=2.09$ & $\mathrm{Rt}=2.18$ \\
C & $77.81^{*}$ & $\mathrm{x}$ & $58.8 \mathrm{ug}$ \\
DM1 & 77.25 & $48.81 \mathrm{uM}$ & $57.24 \mathrm{ug}$ \\
CE & 121.2 & $\mathrm{x}$ & $101.38 \mathrm{ug}$ \\
DM1 + GWA & 74.02 & $\mathrm{x}$ & $139.71 \mathrm{ug}$ \\
\hline
\end{tabular}

* Height peak at Rt (Retention time), mean of 3 rats Statistically nonsignificant. ? = Rt (retention time) amino acid unknown perhaps rest of albumin and result presented peak height in $\mathrm{mV}$ (millivolt).

\section{Discussion}

Beta glucan is a bioactive substance found in G. lucidum, which is considered a nutraceutical food by ANVISA [4]. ANVISA by resolution (Resolution RDC $\mathrm{n}^{\circ} 2$, of 7 of January of 2002) had included beta-glucans with the following allegation: "The beta glucan (alimentary fiber) assists in the reduction of the absorption of the cholesterol. Its consumption must be associated to a balanced diet and healthful habits of life". It is possible to commercialize the fungi in dust, capsule, tablet, being sold as a nutritional supplement in Brazil.

In hydroalcoholic extract of Ganoderma, were found beta glucan, protein and phenols. Many of these phenols act as antioxidant, protecting cells from many metabolic disturbs. Within these, we found in the extract: coumaric acid $(1.46 \mathrm{ug} / \mathrm{mL}) ; 0.20 \mathrm{ug} / \mathrm{mL}$ of cafeic acid; $18.19 \mathrm{ug} / \mathrm{mL}$ of ferulic acid; $2.68 \mathrm{ug} / \mathrm{mL}$ of kercetin; $12.21 \mathrm{ug} / \mathrm{mL}$ of rutin and $15.79 \mathrm{ug} / \mathrm{mL}$ of ganoderic acid. Therefore, the extract was subjected in rats to evaluate a possible diabetes control. Wadt et al. [8] showed that the hydroethanolic extract of Ganoderma did not presented toxicity in a dosage of $1 \mathrm{~mL} / \mathrm{Kg}$ for mice in an acute toxicology assay. There was no significant reduction in body mass, water and feed consumption between the treated and control groups, indicating the safe use of the hydroethanolic extract of Ganoderma lucidum.

Diabetes mellitus (DM) is a plurimetabolic disease of multiple etiology. The long-term effects of this disease include lesions, dysfunction or even failure of multiple organs. The disease is also a public health issue. Metabolic controls of individuals with the evolving disorder contribute to one of the biggest challenges for Brazil's public health services, and worldwide [12]. Many authors describe the use of fungi with medicinal properties for the control of the disease and its complications $[13,14]$.

Regarding the animal model used, many studies have proven that the induction of DM by STZ is an effective method to investigate the mechanism of disease [15]. Considering that Diabetes mellitus is a genetic disease, and that the physiopathological alterations delay appearance, the usage of experimental models for its fast induction has been increasingly considered [16]. According to Delfino et al. [17], a dose of $60 \mathrm{mg} / \mathrm{kg}$ of intraperitoneal STZ has shown to be very effective, and the objective of DM1 induction was achieved. This success was proven when blood glucose levels from induced groups were, after 48 h, 509 mg/dL (DM1 Control group) and 456 mg/dL (DM1 Ganoderma group), therefore showing a significant increase $(p<0.01)$ when compared to the non-induced group.

The treatment with $1.0 \mathrm{~mL} /$ day of Ganoderma lucidum showed to be effective, resulting in a significant decrease in blood glucose levels in the diabetic groups. After 1 week of treatment, the treated group had its glucose levels reduced, from $456 \mathrm{mg} / \mathrm{dL}$ to $383 \mathrm{mg} / \mathrm{dL}$, which corroborates with results 
found by Seto et al. [18] that after the same period, with administration of $0.3 \mathrm{~g} / \mathrm{kg}$ of Ganoderma lucidum extract, the glycemic value decreased from $528 \mathrm{mg} / \mathrm{dL}$ to $428 \mathrm{mg} / \mathrm{dL}$.

This response to treatment may be related to the beta-glucans in G. lucidum, which have the capability to form an aqueous layer in the intestine, reducing the absorption of both sugars and lipids [19].

However, G. lucidum's actions are not limited to glycemic levels. In relation to kidney profile, creatinine, after treatment, showed a significant decrease when compared to the diabetic control group. The same happened with urea. This might be explained by the evidences that G. lucidum delays the harmful effects of DM in kidneys and protects the renal tissue from the possible toxic effects of STZ. Cholesterol levels also had good results, displaying a significant decrease when compared with the DM Control group.

The morphological evaluation of the pancreatic islets revealed compensatory hyperplasia induced by Ganoderma. This finding suggests a stimulatory effect on these cells. These results agree with those observed by Mascaro et al. [20], when using Agaricus as a diabetes control.

Blood plasma is a rich source of biochemical products that can indicate physiological or clinical status of a patient or animal [21,22]. JIANG et al. [23] have fractionation of plasma proteins with $50 \%$ and $70 \%$ ammonium sulphate to reduce interfering substances and improve extraction, thereby facilitating the identification of disease markers. Tryptophan (Trp) is considered an essential amino acid for humans, it is the precursor of proteins and important in regulating molecules, such as serotonin [24] among others. However, it is believed that about $90 \%$ of the peripheral metabolic pathways involving Trp terminate in the production of the so-called kynurenin (Kyn) [25], where ammonium sulfate was used for precipitation at $60 \%$ and dialysis. Results of HPLC demonstrated that diabetic animals present Kyn in higher concentrations when compared with the control group, and when treated with Ganoderma, Trp level was increased in this group. That indicates that Kyn is a product of Trp degradation in pathological conditions, such as DM, and is therefore a disease indicator.

\section{Conclusions}

Evaluation from Ganoderma lucidum extract in STZ-hyperglycemic rats indicated that the extract possesses hypoglycemic and hypolipidemia activities. It is important that more Trp was produced in the blood and that it can the improve health status.

Author Contributions: Conceptualization, E.E.B. and N.S.Y.W.; Methodology, E.E.B., E.M.B.H., A.M.C.M., P.A.M.N. and N.S.Y.W.; Software, E.E.B.; Validation, E.E.B. and N.S.Y.W.; Formal Analysis, E.E.B., E.M.B.H., A.M.C.M., P.A.M.N. and N.S.Y.W.; Investigation, E.E.B. and N.S.Y.W.; Resources, E.E.B. and N.S.Y.W.; Data Curation, E.E.B. and N.S.Y.W.; Writing-Original Draft Preparation, E.E.B., N.S.Y.W. and E.M.B.H.; Writing-Review \& Editing, E.E.B., N.S.Y.W. and E.M.B.H.; Visualization, E.E.B.; Supervision, E.E.B. and N.S.Y.W.; Project Administration, E.E.B.; Funding Acquisition, E.E.B.

Funding: This research was funded by the CNPq grant number (Process 474681/2013).

Acknowledgments: Supported by CNPq for the financial support (Process 474681/2013). We also thank Danilo Wadt for assistance with the manuscript preparation and helpful discussions.

Conflicts of Interest: The authors declare no conflicts of interest.

\section{References}

1. Fang, Q.-H.; Zhong, J.-J. Effect of initial ph on production of ganoderic acid and polysaccharide by submerged fermentation of ganoderma lucidum. Process Biochem. 2002, 37, 769-774. [CrossRef]

2. Berovič, M.; Habijanič, J.; Zore, I.; Wraber, B.; Hodžar, D.; Boh, B.; Pohleven, F. Submerged cultivation of ganoderma lucidum biomass and immunostimulatory effects of fungal polysaccharides. J. Biotechnol. 2003, 103, 77-86. [CrossRef]

3. Urben, A.F. (Ed.) Biologia, morfologia, fisiologia e reprodução de cogumelos. In Produção de Cogumelos por Meio de Tecnologia Chinesa Modificada; Embrapa: Brasília, Brazil, 2004. 
4. Anvisa (National Sanitary Surveillance Agency). Regulamento Técnico de Substâncias Bioativas e Probióticos Isolados com Alegação de Propriedades Funcional e ou De Saúde: Resolução; RDC n. 2, de 7 de janeiro de 2002; Official Gazette of the Federative Republic: Brasilia, Brazil, 2002.

5. Paterson, R.R.M. Ganoderma-a therapeutic fungal biofactory. Phytochemistry 2006, 67, 1985-2001. [CrossRef] [PubMed]

6. Yan, K.; Zhang, W.; Yu, H.; Wang, H.; Zhang, X. New polysaccharide compounds derived from submerged culture of Ganoderma lucidum and Lycium barbarum. Food Technol. Biotechnol. 2010, 48, 94-101.

7. Zhu, X.-L.; Chen, A.-F.; Lin, Z.-B. Ganoderma lucidum polysaccharides enhance the function of immunological effector cells in immunosuppressed mice. J. Ethnopharmacol. 2007, 111, 219-226. [CrossRef] [PubMed]

8. Wadt, N.; Okamoto, M.; Hi, E.; Bach, E. Chemical, toxicological, anti-inflammatory and antimicrobial evaluation of ganoderma lucidum extracts. Emir. J. Food Agric. 2015, 27, 577-584. [CrossRef]

9. Lowry, O.H.; Rosenbrough, N.J.; Farr, A.L.; Randall, R.J. Protein measurement with the Folin phenol reagent. J. Biol. Chem. 1951, 193, 265-275. [PubMed]

10. Swain, T.; Hillis, W.E. The phenolic constituents ofprunus domestica. I.-The quantitative analysis of phenolic constituents. J. Sci. Food Agric. 1959, 10, 63-68. [CrossRef]

11. Lever, M. A new reaction for colorimetric determination of carbohydrates. Anal. Biochem. 1972, 47, $273-279$. [CrossRef]

12. Sartorelli, D.S.; Franco, L.J.; Cardoso, M.A. Nutritional intervention and primary prevention of type 2 diabetes mellitus: A systematic review. Cad. Saúde Pública 2006, 22, 7-18. [CrossRef] [PubMed]

13. Yu, S.-L.; An, Y.J.; Yang, H.; Kang, M.-S.; Kim, H.-Y.; Wen, H.; Jin, X.; Kwon, H.N.; Min, K.-J.; Lee, S.-K.; et al. Alanine-metabolizing enzyme alt1 is critical in determining yeast life span, as revealed by combined metabolomic and genetic studies. J. Proteome Res. 2013, 12, 1619-1627. [CrossRef] [PubMed]

14. Rahar, S.; Swami, G.; Nagpal, N.; Nagpal, M.A.; Singh, G.S. Preparation, characterization, and biological properties of $\beta$-glucans. J. Adv. Pharm. Technol. Res. 2011, 2, 94-103.

15. Akbarzadeh, A.; Norouzian, D.; Mehrabi, M.R.; Jamshidi, S.; Farhangi, A.; Verdi, A.A.; Mofidian, S.M.A.; Rad, B.L. Induction of diabetes by streptozotocin in rats. Indian J. Clin. Biochem. 2007, 22, 60-64. [CrossRef] [PubMed]

16. Roselino, M.N.; Pauly-Silveira, N.D.; Cavallini, D.C.; Celiberto, L.S.; Pinto, R.A.; Vendramini, R.C.; Rossi, E.A. A potential synbiotic product improves the lipid profile of diabetic rats. Lipids Health Dis. 2012, 11, 114. [CrossRef] [PubMed]

17. Delfino, V.D.A.; Figueiredo, J.F.; Matsuo, T.; Favero, M.E.; Matni, A.M.; Mocelin, A. Diabetes mellitus induzido por estreptozotocina: Comparação em longo prazo entre duas vias de administração. J. Bras. Nefrol. 2002, 24, 31-36.

18. Seto, S.W.; Lam, T.Y.; Tam, H.L.; Au, A.L.S.; Chan, S.W.; Wu, J.H.; Yu, P.H.F.; Leung, G.P.H.; Ngai, S.M.; Yeung, J.H.K.; et al. Novel hypoglycemic effects of ganoderma lucidum water-extract in obese/diabetic $(+\mathrm{db} /+\mathrm{db})$ mice. Phytomedicine 2009, 16, 426-436. [CrossRef] [PubMed]

19. Shao, Y.; Guo, Y.; Wang, Z. $\beta-1,3 / 1,6$-glucan alleviated intestinal mucosal barrier impairment of broiler chickens challenged with salmonella enterica serovar typhimurium. Poult. Sci. 2013, 92, 1764-1773. [CrossRef] [PubMed]

20. Mascaro, M.B.; França, C.M.; Esquerdo, K.F.; Lara, M.A.N.; Wadt, N.S.Y.; Bach, E.E. Effects of dietary supplementation withagaricus sylvaticusschaeffer on glycemia and cholesterol after streptozotocin-induced diabetes in rats. Evidence-Based Complement. Altern. Med. 2014, 2014, 1-10.

21. Anderson, N.L. The Human Plasma Proteome: History, Character, and Diagnostic Prospects. Mol. Cell. Proteom. 2002, 1, 845-867. [CrossRef]

22. Tanaka, Y.; Akiyama, H.; Kuroda, T.; Jung, G.; Tanahashi, K.; Sugaya, H.; Utsumi, J.; Kawasaki, H.; Hirano, H. A novel approach and protocol for discovering extremely low-abundance proteins in serum. Proteomics 2006, 6, 4845-4855. [CrossRef] [PubMed]

23. Jiang, L.; He, L.; Fountoulakis, M. Comparison of protein precipitation methods for sample preparation prior to proteomic analysis. J. Chromatogr. Coruña 2004, 1023, 317-320. [CrossRef] 
24. Grohmann, U.; Fallarino, F.; Bianchi, R.; Orabona, C.; Vacca, C.; Fioretti, M.C.; Puccetti, P. A defect in tryptophan catabolism impairs tolerance in nonobese diabetic mice. J. Exp. Med. 2003, 198, 153-160. [CrossRef] [PubMed]

25. Oxenkrug, G.F.; Turski, W.A.; Zgrajka, W.; Weinstock, J.V.; Summergrad, P. Tryptophan-kynurenine metabolism and insulin resistance in hepatitis c patients. Hepat. Res. Treat. 2013, 2013, 1-4. [CrossRef] [PubMed] 